\title{
Kenny Music Performance Anxiety Inventory: Confirmatory factor analysis of the Spanish version
}

Psychology of Music 2016, Vol. 44(3) 340-352 (C) The Author(s) 2015

Reprints and permissions: sagepub.co.uk/journalsPermissions.nav DOI: $10.1177 / 0305735614567932$ pom.sagepub.com

@SAGE

\section{Francisco Javier Zarza Alzugaray', Santos Orejudo Hernández ${ }^{2}$, Oscar Casanova López' ${ }^{1}$ and Beatriz Mazas Gil}

\begin{abstract}
This article presents the process of adjusting into Spanish Kenny's Music Performance Anxiety Inventory (Kenny, Davis, \& Oates, 2004). This questionnaire is based on Barlow's theory of performance anxiety and evaluates levels of anxiety whilst on stage. After doing two translations into Spanish, a peer review, and pilot study, the questionnaire was answered by 490 musicians training in six Spanish music conservatories. Results showed that the adapted version of the instrument, with some minor modifications, has good psychometric properties, also validated through a confirmatory factor analysis procedure. Thereof, and in accordance with to Barlow's theoretical framework, we saw emerge three related factors that made reference to specific cognitions of performance anxiety, such as helplessness as a factor of psychological vulnerability and early family influences. Performance anxiety is related to a psychological vulnerability profile and early relationship context. Finally, it is important to count with reliable instruments that allow contrasting theories in different cultural background, comparing the effects of problems or treatment outcomes.
\end{abstract}

\section{Keywords}

assessment, confirmatory factor analysis, conservatory students, music performance anxiety, self-report

MPA (Musical Performance Anxiety) experienced by musicians who are undergoing training is one of the most significant problems occurring in the practice and study of music. To many people who yearn for success in their pursuit of a professional musical career, performance anxiety can represent a formidable obstacle

\footnotetext{
${ }^{1}$ Department of Musical, Plastic and Body expression, Faculty of Education, University of Zaragoza, Spain

${ }^{2}$ Department of Psychology and Sociology, Faculty of Education, University of Zaragoza, Spain

${ }^{3}$ Department of Didactics of Experimental Science, Faculty of Education, University of Zaragoza, Spain
}

\section{Corresponding author:}

Francisco Javier Zarza Alzugaray, Department of Musical, Plastic and Body expression, Faculty of Education,

University of Zaragoza, Pedro Cerbuna 12, 50009 Zaragoza, Spain.

Email: fjzarza@unizar.es 
Performance anxiety affects musicians worldwide (Yoshie, Kudo, Murakoshi, \& Ohtsuki, 2009). According to Dalia Cirujeda (2004), approximately $20 \%$ of students who have enrolled in tertiary music conservatories eventually drop out because they suffer from performance anxiety - that is, the inability to control their 'nerves' when they flare up before a concert or exam. Of those who continue studying, between $40 \%$ and $60 \%$ experience a decrease in the quality of their musical performance due to anxiety (Marchant-Haycox \& Wilson, 1992). The same anxiety occurs with musicians in the course of their professional careers (Van Kemenade, Van Son, \& Van Heesch, 1995). In 2002, Kaspersen and Götestam worked with a Norwegian sample of 126 tertiary music conservatory students and found that $36.5 \%$ of their subjects required assistance in solving problems associated with performance anxiety.

Not all occurrences of anxiety necessarily have negative effects. Researchers such as Kenny, Fortune, and Ackermann $(2009,2013)$ acknowledge that a certain degree of anxiety is beneficial by helping the musician attain the required threshold of physiological arousal to ensure an excellent performance in public. Similarly, the Yerkes-Dodson law states that a zone of optimal performance is associated with certain trigger levels, above or below which performance inevitably decreases. Thus, performance anxiety is not always problematic (Herrera \& Manjón, 2013; Papageorgi, Creech, \& Welch, 2011). In some cases, however, it has been noted that performance anxiety can generate an inability to perform in public (Lee, 2002; Nagel, Himle, \& Papsdorf, 1981, Wolfe, 1989). Such experiences can lead students, in turn, to entirely abandon what might otherwise have been a promising musical career (Wesner, Noyes, \& Davis, 1990). Therefore, establishing the nature of the relationship between musical performance and performance anxiety can be of use not only to help musicians avoid leaving the career, but also as knowledge they can apply in their daily professional lives.

In this regard, we should note that music-making is a discipline that requires a number of different high-level skills: focused attention, memory, and physical coordination, coupled with aesthetic and interpretative abilities. Such skills usually undergo improvement through years of solitary practice during which the participant submits him/herself to intense, continual self-evaluation on a daily basis (Kenny, Davis, \& Oates, 2004). However, applying those skills in front of an audience presents a situation quite different from solitary practice. Seen from this angle, the key element in a public performance is that it becomes an evaluation by others - one of the central components of performance anxiety (Kenny \& Osborne, 2006; Papageorgi, Hallam, \& Welch, 2007)

The problem of performance anxiety in musicians has been described and defined in a variety of ways. These include 'being nervous before a performance,' a series of definitions proposed over many years in clinical psychology, and recollections stemming from renowned musicians such as Chilean pianist Claudio Arrau, who wrote of 'a fear so intense that it blots out the singers' high notes, causing all mastery and technique to vanish into nothing' (Arrau, 1983, p. 9). Performance anxiety has also been defined as 'the experience of persisting, distressful apprehension about and/or actual impairment of performance skills in a public context, to a degree unwarranted given the individual's aptitude, training, and level of preparation' (Salmon, 1990, p. 3).

It is largely agreed that MPA is characterized by an evident and perceptible fear of appearing in front of an audience (American Psychiatric Association, 1994; Kenny, 2008, Salmon, 1990, Studer Danusera, Hildebrand, Arial, \& Gomez, 2010; Wilson, 1997). Furthermore, performance anxiety has three distinct components, commonly designated as cognitive, physiological and behavioural (Osborne, Kenny, \& Holsomback, 2005). In fact, at a given moment of public exposure, and in view of the temporal aspect of this problem, people with performance anxiety may experience cognitive difficulties such as memory lapses or the inability to reason properly, accompanied by negative thoughts related to the act of performing or about themselves. Physiological 
problems can appear: sweaty palms, hands, arms, trembling legs and knees, a dry mouth, a trembling of the voice, accelerated pulse, gastrointestinal difficulties, loss of appetite, nausea, and even vomiting or insomnia. Certain affected participants adopt behavioural strategies such as evasion or escape. Depending on the intensity of the above-described symptoms and the way they may interfere with performance, some form of treatment may be called for (Lee, 2002; McAllister, 2011; Petrovich, 2004; Sandgren, 2002; Spahn, 2006; Taborsky, 2007).

To address this problem experienced by musicians undergoing training, we need to develop theories capable of explaining what causes MPA and how it progresses. Such theories, in turn, will enable us to propose methods of treatment and to design a series of valid, reliable assessment tools. This article attempts to address this need within the context of Spain: although several useful self-report measures are currently being applied in this field, none of them have been adapted or specifically validated in the context of Spanish educational situations. In Spain, the absence of those tools keeps us from gaining a deeper understanding of the problem, and hinders us from conducting cross-cultural comparisons (for instance, by cross-validating theories or comparing treatment methods in different countries). Therefore, in this study we propose to develop a Spanish adaptation of Kenny's Music Performance Anxiety Inventory, also known as K-MPAI (Kenny et al., 2004).

The K-MPAI (Kenny et al., 2004) is a specific tool based on Barlow's (2000) model and designed to measure performance anxiety in musicians. The Barlow model features three factors or vulnerabilities capable of generating anxiety. First is a generalized biological vulnerability which is heritable: such biological factors can influence the development of anxiety disorders and negative affect. Second, generalized psychological vulnerability is based on early experiences and the sensation that certain events are uncontrollable: early on in life and under certain conditions, adverse experiences can lead to a greater degree of psychological vulnerability, to the point where some adults may even experience anxiety and negative affect as an omnipresent condition. Third, Barlow's model proposes a more specific psychological vulnerability: the experience of anxiety can be determined by specific environmental stimuli and reinforced through different types of learning (i.e., conditioned or vicarious). This last type of vulnerability is a necessary condition for anxiety to appear, accompanied by the other two which are present in the origins of particular anxiety disorders such as specific phobias or social phobia (Barlow, 2000; Kenny et al., 2004; Kenny \& Osborne, 2006).

Kenny (2009a, 2009b) readjusts Barlow's (2000) model and explains anxiety as an interaction occurring among three factors which can cause a greater or lesser degree of anxiety response: first, the context of early interactions and relationships; second, psychological vulnerability or helplessness; and third, concerns specifically related to a proximal performance situation. Several different versions of this assessment tool have been proposed; all have been validated and published within the musical field, and display good psychometric properties (Kenny \& Ackermann, 2015).

There have been two published versions of the K-MPAI - the 26-item original version (Kenny et al., 2004) and the modified 40-item questionnaire (2009). The 26-item version has been permanently superseded by the 40-item version (Kenny, 2009b). There is also a 15-item MPAI-A for adolescents, a state-based inventory designed specifically for adolescents aged 1218 years attending specialist music schools. The psychometric properties of the 40 -item K-MPAI have been explored with a population of (Australian) professional musicians and samples of tertiary-level student musicians from Australia and New Zealand. The psychometric properties of the K-MPAI have been reported in Kenny (2011), Kenny, Driscoll, and Ackermann (2014), and Kenny \& Ackermann (2015). There have now been certified translations of the 40-item version of the K-MPAI into Brazilian Portuguese, French, German, Italian, Polish, Portuguese, Spanish. 
Recently, Figueirido Rocha, Dias-Neto, and Farid Gattaz (2011), using the Brazilian Portuguese translation of K-MPAI with 218 professional and amateur musicians from Brazil, reported very high internal consistency for the K-MPAI (Cronbach alpha of 0.957), a correlation of 0.642 with Spielberger, Gorsuch, and Lushene's (1970) test of state-trait anxiety (STAI), and a normal distribution of anxiety scores. In this study, we thus adapted the K-MPAI instrument to measure performance anxiety in Spanish musicians. Furthermore, since the K-MPAI is based on Barlow's theory of performance anxiety (2000), we intend to explore whether Barlow's model is supported in a cultural context such as this one. Finally, we wish to make further progress in the validation of this measure within a theoretical framework, analysing its internal structure in a sample taken from a culture different to the previous ones. Although several studies to date have applied exploratory factor analysis (Figueirido Rocha et al., 2011; Kenny, 2009b; Kenny et al., 2004), no studies in this field have yet applied confirmatory factor analysis (Brown, 2006) or other techniques capable of providing greater support for a theoretical framework.

\section{Method}

\section{Participants}

The sample comprised 490 tertiary students studying for a higher degree in music, of which $54.0 \%$ were male and $46.0 \%$ female. They were enrolled in 6 music conservatories in Spain. At this level of training, equivalent to an undergraduate degree in music, the aim is to become a professional musician, not just to learn music as a hobby or as part of an extracurricular activity. The sample mean age was 22.62 years (SD 4.73), ranging from 16 to 50 years. On average, participants had been learning music for 13.83 years, in instrumental specialties including: flute (38 participants), violin (75), piano (66), classical guitar (23), harp (3), double bass (13), bassoon (9), viola (24) clarinet (42), conducting (4), organ (2), cello (31), trombone (13), horn (22), drums (13), voice (21), accordion (2) saxophone (30), trumpet (25), tuba (8), oboe (9), euphonium (4), composition (2), Baroque transverse flute (1), recorder (2), flamenco guitar (2) and plucked strings other than guitar (3). Three participants did not indicate which instrument they studied.

\section{Materials}

We adapted the K-MPAI questionnaire as proposed in Kenny et al. (2004) into Spanish and validated it. This version consists of 26 items rated on a 7-point Likert scale. A high score on a certain item indicates the presence of the evaluated attribute. Items are grouped into three theoretical factors (Kenny, 2009a, 2009b):

- The context of early interactions: items 5, 9, 19, 21, 24. According to Barlow (2000), these items measure early contextual vulnerability.

- Generalized psychological vulnerability: items 1, 2, 3, 4, 6, 8, 10, 11, 15, 16, 17, 18, 23. These items evaluate the presence of a general factor associated with helplessness as an indicator of personal vulnerability.

- Concerns about performance, which are the most specific indicators of performance anxiety: items 7, 12, 13, 14, 20, 22, 25, 26.

\section{Procedure}

In order to formulate the K-MPAI in Spanish, appropriate backwards translations were undertaken during the translation process. We then asked three experts from the fields of musical 
education and psychology to validate this measure's comprehensiveness and its suitability for the Spanish musical environment. After having reviewed all items and assessed their relevance, appropriateness and validity, the three experts approved the questionnaire. Once the Spanish version of the questionnaire was ready, we administered it to a small group and subsequently to the entire sample.

The sample was collected via non-random sampling. Directors of all tertiary music conservatories in Spain were contacted with a request for assistance with this research project. In the case of an affirmative response, a date for data collection was agreed upon with each institution in advance; on the selected date, one of our research team members visited the conservatoire in person. Participants received the questionnaire in pen-and-paper format, with the researcher and the students all present within the framework of a normal class session. Thus, all students attending the class took part in the research. Response anonymity was ensured, and we emphasised that participation was entirely voluntary.

\section{Statistical procedure}

In order to adapt the K-MPAI, we followed the usual measure validation method, that is, individual item analysis according to classical test theory approach (Abad, Olea, Ponsoda, \& García, 2011) and factor analysis techniques, both exploratory and confirmatory (Brown, 2006). For this purpose, we established two randomly independent sub-samples. For each, we used a different type of analysis: exploratory factor analysis in the first sample $(n=215)$, and confirmatory factor analysis in the second $(n=275)$. Our exploratory factor analysis (EFA) followed the method of principal components, retaining all factors with eigenvalues greater than one, and then applying an oblimin rotation resulting in a matrix of related factors. To test its feasibility, we took into account statistical values from Kaiser, Meyer, and Olkin, as well as Bartlett's test of sphericity (Abad et al., 2011). Throughout this analysis we used SPSS 19.00.

In the confirmatory factor analysis (CFA), a three-factor model derived from all the items was compared with Barlow's (2000) three-factor model. Subsequently, taking into account the corresponding adjustments in the global model along with modifications in the index and in the estimated values, we developed a new model (see the Results section). The estimation method used was Maximum Likelihood, once the fulfilment of assumptions of multivariate normality in data had been established by applying different model adjustment indicators, namely CMIN/ DF, CFI and RMSEA statistics - the most common indicators recommended by authors such as Brown (2006) and also McDonald and Ho (2002). We conducted this portion of our analysis using the statistical application AMOS 17.0.

\section{Results}

\section{Reliability and descriptive analysis}

The K-MPAI Spanish version overall has a Cronbach's alpha of 0.866; its distribution fits well with a normal curve (kurtosis $=0.27$ ) and it has good symmetry (skewness $=1.99$ ): this is thus an instrument with good internal consistency. This is reinforced by its low-variability Cronbach $\alpha$ index which never exceeds 0.02 , even when elements of the scale are eliminated. The average value of the items is $3.41(S D=1.69)$, close to the theoretical scale value of 4 . However, some values lie further from the mean: items $6,7,11,21$, and 23 fall more than 1.5 points below the theoretical mean, and the standard deviation is below average. Most of the items correlate significantly with the total scale $(>0.30$ ), with many correlations between 0.4 and 0.5 (items 10 , $11,14,16,17,18,20$, and 22). This indicates a strong and direct relationship between the full 
scale and the individuality of each item. However, several items have lower correlation coefficients $(<0.30)$ (items 2, 8, and 19).

\section{EFA}

Bartlett's test is $\chi 2=3669.22$ and $p<.001$ for the whole sample, allowing us to affirm that the correlation matrix is not an identity matrix. In addition, the Kaiser-Meyer-Olkin test has a value of 0.902. In the analysis of the sub-sample with $N_{1}=215$ (Cronbach $\alpha=0.859$; kurtosis $=$ 0.96; skewness $=1.81$ ) we found that Bartlett's test of sphericity and the KMO test reported a $\chi^{2}$ of 1672.91 for $p<.001$, and a KMO of 0.870 , thus confirming the relevance of an exploratory factorial reduction of items.

From these results the 26 questions can be grouped into seven factors with eigenvalues greater than 1, which explain $58.26 \%$ of the total variance: in their extraction, they present commonalties ranging from 0.773 (Item 2) to 0.437 (Item 26; see Table 1). Concurrently, items 8 and 2 are each associated with a single factor (factors 6 and 7, respectively).

In Table 1 we see two factors relating to the EFA items related to helplessness and two factors relating to specific cognitions in the five factors obtained. This grouping of items corresponds with the predicted theoretical content; however, it doubles the number of factors listed in the model. Thus we carried out a second EFA, reducing the solution to five factors: the results are presented in Table 1 . In this new version, items 2 (relating to early relationships context) and 8 (relating to helplessness) saturate in two of the established factors, indicated by the factorial weights of zero.

\section{CFA}

In view of the EFA's lack of parsimony, and considering that K-MPAI is a measure supported by a theoretical model, we ran a confirmatory factor analysis on a second sub-sample $(N=275)$. We initially proposed an adjustment model with three factors, applying the distribution as used in Kenny (2009b). This first model had a generally acceptable goodness of fit, which, however, was not optimal. We then obtained a CMIN/DF value of 2.68; generally, however, a fit index is only considered tolerable if it is less than or equal to 2.5 (Sommer, 2013; Weiber \& Mülhlhaus, 2009). The RMSEA (root mean square error of approximation) was 0.078: again, this is higher than the theoretically desirable value, which would need to be less than 0.06 . The comparative index adjustment (CFI) was 0.752 , also lower than theoretically recommended (Table 2).

Apart from the problems encountered in the adjusted global model, items 2, 5, 8, and 26 (respectively: I find it easy to trust others; Worrying too much is a characteristic of my family; I find it difficult to depend on others; My memory is very reliable) have low factor weights - not significantly different than zero $(\leqslant 0.30)$ : $0.09,0.09,0.03$ and 0.22 , respectively.

Thus, taking the modification indices into account, we propose a second model (Figure 1) where we establish a value of 0 for the factorial weight of items 2 and 8 . Meanwhile, four items of helplessness transfer to specific cognitions $(10,15,17$, and 18) and one of the items from specific cognitions transfers to helplessness (item 26), to which an additional item is added, that of early experience context (item 5). We have also allowed one item (21) to exert factorial weight on two different factors (helplessness and context). Finally, this model incorporates covariance estimation errors for items 26 and 14, 1 and 16, 6 and 23, and 1 and 4 .

As can be seen in Table 1, this three-factor model fits this sample's data relatively well, providing factorial loadings ranging between 0.50 and 0.80 for most items. The resulting factors are equally consistent with Barlow's (2000) theory. Thus, the factor associated with specific 
Table I. Factorial weights of items in 3, 4, and 5 factors models of KMPAI.

\begin{tabular}{|c|c|c|c|c|c|c|c|c|}
\hline \multirow[t]{3}{*}{ Item } & \multicolumn{6}{|l|}{ AFE 5 Factors } & \multirow{3}{*}{$\begin{array}{l}\text { CFA - } 3 \\
\text { factors } \\
\begin{array}{l}\text { Factorial } \\
\text { weight }\end{array}\end{array}$} & \multirow{3}{*}{$\begin{array}{l}\begin{array}{l}\text { CFA - } 4 \\
\text { factors }\end{array} \\
\begin{array}{c}\text { Factorial } \\
\text { weight }\end{array}\end{array}$} \\
\hline & \multirow[t]{2}{*}{ Communalities } & \multicolumn{5}{|c|}{ Factors } & & \\
\hline & & 1 & 2 & 3 & 4 & 5 & & \\
\hline KMPAI 1/ Helplessness* & 0.47 & & & & 0.44 & & 0.59 & 0.57 \\
\hline KMPAI 3/ Helplessness** & 0.41 & & 0.50 & & & & 0.53 & 0.52 \\
\hline KMPAI 4/ Helplessness* & 0.49 & & & & 0.60 & & 0.61 & 0.61 \\
\hline KMPAI 5/ Helplessness* & 0.52 & & & & 0.71 & & 0.41 & 0.40 \\
\hline KMPAI 6/ Helplessness** & 0.59 & & 0.75 & & & & 0.58 & 0.60 \\
\hline KMPAI 8/ Helplessness & 0.29 & & & & 0.46 & & 0.00 & 0.00 \\
\hline KMPAI 11/ Helplessness** & 0.59 & & 0.71 & & & & 0.70 & 0.70 \\
\hline KMPAI 16/ Helplessness* & 0.53 & & & & 0.41 & & 0.55 & 0.55 \\
\hline KMPAI 21/ Helplessness** & 0.36 & & 0.53 & & & & 0.41 & 0.49 \\
\hline KMPAI 23/ Helplessness** & 0.65 & & 0.81 & & & & 0.56 & 0.57 \\
\hline KMPAI 26/ Helplessness** & 0.32 & 0.54 & & & & & 0.23 & 0.23 \\
\hline $\begin{array}{l}\text { KMPAI 7/ Specific } \\
\text { cognitions }\end{array}$ & 0.31 & & & & & & 0.42 & 0.42 \\
\hline $\begin{array}{l}\text { KMPAI 10/ Specific } \\
\text { cognitions }\end{array}$ & 0.57 & 0.57 & & & & & 0.59 & 0.60 \\
\hline $\begin{array}{l}\text { KMPAI 12/ Specific } \\
\text { cognitions }\end{array}$ & 0.51 & 0.68 & & & & & 0.54 & 0.54 \\
\hline $\begin{array}{l}\text { KMPAI 13/ Specific } \\
\text { cognitions }\end{array}$ & 0.51 & 0.43 & & & & & 0.64 & 0.64 \\
\hline $\begin{array}{l}\text { KMPAI 14/ Specific } \\
\text { cognitions }\end{array}$ & 0.56 & 0.73 & & & & & 0.56 & 0.57 \\
\hline $\begin{array}{l}\text { KMPAI 15/ Specific } \\
\text { cognitions }\end{array}$ & 0.51 & 0.43 & & & & & 0.59 & 0.57 \\
\hline $\begin{array}{l}\text { KMPAI 17/ Specific } \\
\text { cognitions }\end{array}$ & 0.51 & 0.60 & & & & & 0.60 & 0.60 \\
\hline $\begin{array}{l}\text { KMPAI 18/ Specific } \\
\text { cognitions }\end{array}$ & 0.56 & & & & & 0.47 & 0.69 & 0.68 \\
\hline $\begin{array}{l}\text { KMPAI 25/ Specific } \\
\text { cognitions }\end{array}$ & 0.45 & 0.65 & & & & & 0.65 & 0.65 \\
\hline $\begin{array}{l}\text { KMPAI 20/ Specific } \\
\text { cognitions }\end{array}$ & 0.52 & 0.68 & & & & & 0.63 & 0.64 \\
\hline $\begin{array}{l}\text { KMPAI 22/ Specific } \\
\text { cognitions }\end{array}$ & 0.68 & 0.70 & & & & & 0.81 & 0.81 \\
\hline $\begin{array}{l}\text { KMPAI 2/ Early } \\
\text { relationship context }\end{array}$ & 0.34 & & & & & 0.51 & 0.00 & 0.00 \\
\hline $\begin{array}{l}\text { KMPAI 9/ Early } \\
\text { relationship context }\end{array}$ & 0.63 & & & 0.75 & & & 0.63 & 0.20 \\
\hline $\begin{array}{l}\text { KMPAI 19/ Early } \\
\text { relationship context }\end{array}$ & 0.58 & & & 0.71 & & & 0.57 & 0.12 \\
\hline $\begin{array}{l}\text { KMPAI 24/ Early } \\
\text { relationship context }\end{array}$ & 0.58 & & & 0.69 & & & 0.60 & 0.19 \\
\hline
\end{tabular}

*Helplessness depression symptoms.

**Uncontrollability symptoms. 
Table 2. CFA adjustment values of original model and 3, 4 and 5 factors models of KMPAI.

\begin{tabular}{lcccc}
\hline & $\begin{array}{l}\text { Model 1 (Kenny, } \\
\text { 2009b) }\end{array}$ & $\begin{array}{l}\text { Adapted model } \\
\text { 3 factors }\end{array}$ & $\begin{array}{l}\text { Adapted model } 4 \\
\text { factors }\end{array}$ & $\begin{array}{c}\text { Adapted model } \\
\text { five factors }\end{array}$ \\
\hline Chi-square & & 875.323 & 759.716 & 719.975 \\
$d f$ & 586 & 490 & 482 \\
CMIN/DF & 2.68 & 1.494 & 1.550 & 1.492 \\
RMSEA & 0.078 & .032 & .034 & .032 \\
CFI & 0.752 & .916 & .921 & .930 \\
ACAIKE & & 1211.303 & 1075.716 & 1051.975 \\
PRATIO & & .902 & .888 & .873 \\
PCFI & & .826 & .818 & .812 \\
\hline
\end{tabular}

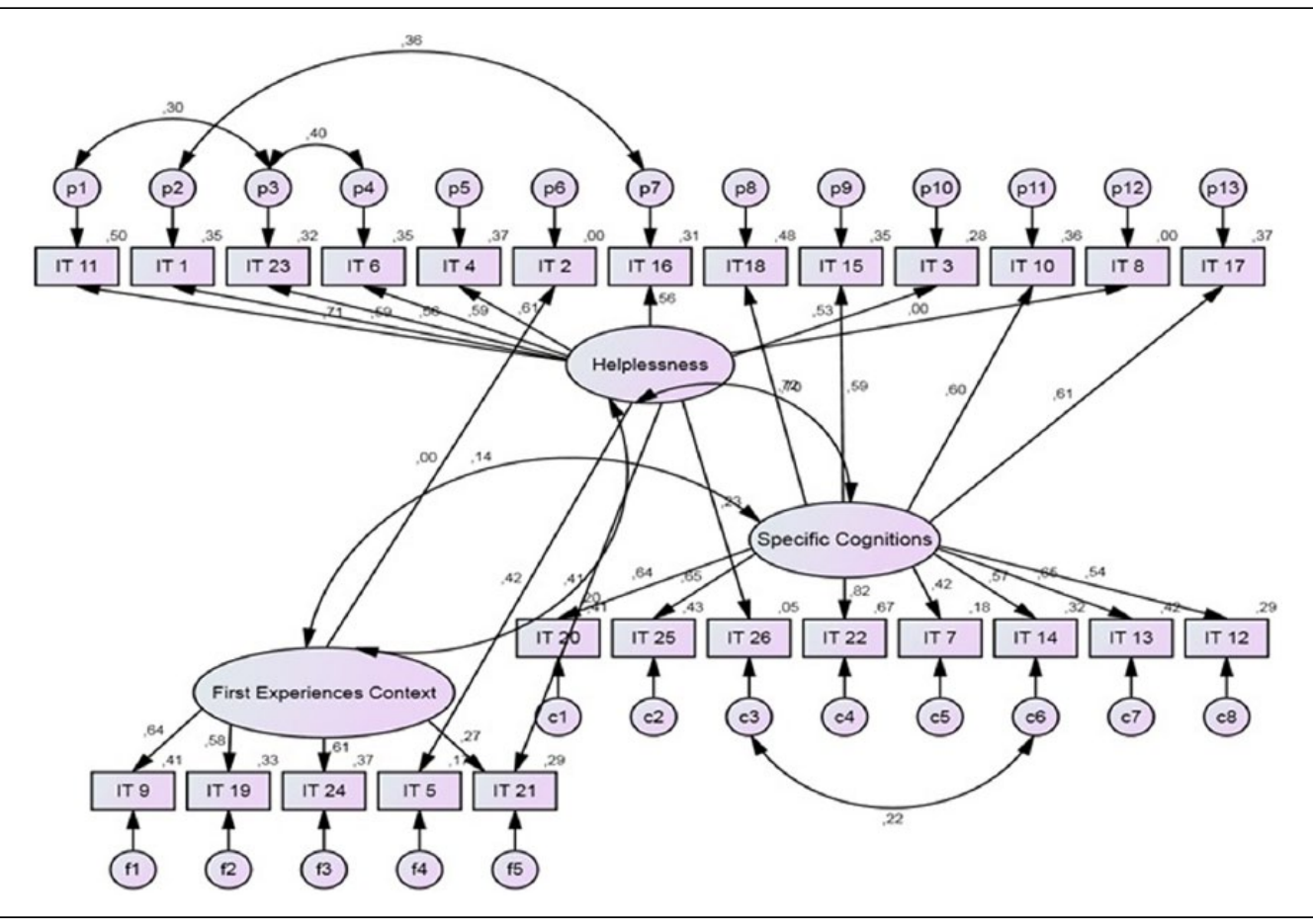

Figure I. KMPAI three factors model.

cognitions refers to specific cognitions associated with stage fright or related to the specific psychological vulnerability factor in Barlow's (2000) theory, and assumes the role of evaluating aspects most closely associated with musical performance in public. Thus, the prime factor of specific negative cognition consists of items $7,10,12,13,14,15,17,18,20,22$, and 25.

Furthermore, the helplessness factor is associated with the general psychological vulnerability factor described by Barlow (2000): factor 2, 'Helplessness,' corresponds to items 1, 3, 4, 5, $6,11,16,21,23$, and 26. Finally, a third factor is derived from an adjustment proposed to Barlow's (2000) theory by Kenny et al. (2004) and Kenny (2009a, 2009b). They introduced an additional factor related to the overall - not specifically musical - learning situation as 
Table 3. Sub-scale distributions.

\begin{tabular}{lrrll}
\hline & Mean & \multicolumn{1}{c}{$S D$} & Kurtosis & Skewness \\
\hline Specific cognition factor (11 items) & 40.23 & 12.80 & 1.95 & 0.73 \\
Helplessness factor (10 items) & 32.28 & 9.68 & 0.49 & 3.20 \\
Contextual factor (3 items) & 8.79 & 3.85 & 1.01 & 6.74 \\
Total & 88.87 & 21.24 & 1.954 & 0.73 \\
\hline
\end{tabular}

experienced very early on in a family context. Those items fit here in factor 3, 'Family context,' items 9, 19, 21, and 24.

By submitting the second sub-sample $(N=215)$ to the same analysis, we found that estimations do not differ from the first $(N=275)$, and we can therefore apply the following adjustment obtained in the model test on the sample used for confirmatory analysis $(N=275)$ : it presents the following values: $\mathrm{CMIN} / \mathrm{DF}=1,494(\leqslant 2.5), \mathrm{RMSEA}=0.03(\leqslant 0.06)$ and CFI $=0.916(>$ 0.9 ), as shown in Table 2. The final grouping of items into the corresponding factors can be viewed in Table 1 and Figure 1.

Analysing the reliability of this new factorial distribution, the category of 'helplessness' has a Cronbach $\alpha$ of 0.786 , 'specific cognitions' 0.868 and 'early relationships context' 0.568 . This last category has the lowest internal consistency since it comprises four components, and Cronbach's $\alpha$ is highly sensitive to the number of statistical items. However, correlations obtained between factors yield a value of 0.72 for the categories of helplessness and specific cognitions, 0.20 for the early relationships context and helplessness, and 0.13 for the early relationships context and specific cognitions.

In addition to testing the reliability of these different scales, it is important to study how the sub-scales behave in comparison with a normal distribution. The details for each sub-scale are shown in Table 3. On the whole, we find that it fits well with a normal curve.

In order to explore further CFA options and in accordance with the EFA shown in Table 2, we decided to test an additional five-factor model. In the first results, items 2 and 8 had a factor weight not significantly different from zero, just as in the previous three-factor model; so we again removed those two items. After this adjustment, results displayed acceptable goodness of fit (Table 2). A comparison between both models favours this five-factor model ( $\Delta$ chi-square $=$ 155, G.L.104, $p<.001$ ) in terms of global and comparative fit; however, since the five-factor model is less parsimonious, both models present acceptable fit. Nonetheless, this new model challenges the bidimensionality of the two 'helplessness' subfactors and the two 'specific cognitions' subfactors, since their respective correlations are high (.626 and .961). Thus we finally tested a further four-factor model, maintaining the 'specific cognitions' items but grouping them into a single factor, while leaving the two 'helplessness' subfactors separate. This new model, whose GFI data are gathered in Table 2, also presents good global fit values. However, in terms of fit, it is not preferable to the initial three-factor model ( $\Delta$ chi-square $=115,607$, G.L.96, $p=.08$ ), and it compares less favourably with the five-factor model ( $\Delta$ chi-square $=39,741$, G.L. $8, p<$ .001). To summarize: the three-factor model achieves an acceptable global fit, but the four- and five-factor models, although equally well adjusted to the data, produce losses in parsimony.

\section{Discussion and conclusion}

This study's goal was to translate into Spanish and adapt a performance anxiety measure that has previously received favourable theoretical validation in other languages. Until now, no 
other study of this type had been conducted in Spain. The importance of this research is twofold. First, it adapts a useful measure for evaluating performance anxiety into Spanish, thus presenting a tool that professionals will be able to use to identify subjects suffering from this problem and also to evaluate the effectiveness of treatment (certain therapeutic intervention programs are already showing encouraging results, cf. Hoffman \& Hanrahan, 2012). However, to achieve this on a long-term basis it will be necessary to develop theories regarding this problem's origins and development that also include the interaction of personal and contextual factors. Based on this theoretical model, the adaptation of K-MPAI into Spanish will also enable us to gain a better understanding of the particularities of this problem's occurrence within the Spanish culture.

We elected to adapt the K-MPAI questionnaire because it was designed within a particular theoretical framework designed to explain risk factors that play a role in the emergence of MPA. Indeed, we have noted a relation between two vulnerability factors identified by Barlow (2000): previous personal characteristics and early family context. We should note that the former are more strongly connected with anxiety than the latter, which tends to act more as antecedents of personal vulnerability. Therefore, further studies should be conducted on the 40-item version of the inventory in order to further explore interactions between the factors found in the 26 -item version, particularly with the aim of assessing specific vulnerability factors proposed by the model which are specified in the 40-item version of the inventory. They may play a relevant role in the origins and perpetuation of MPA, and might include factors such as the degree of repertoire preparation, the kind of repertoire, previous adverse experiences, the type of performance situation, etc. (Papageorgi et al., 2007). Nevertheless, in this sample of Spanish music students we have found clear support for this theory, and our research highlights the significant role played by personal characteristics as a contributing factor in performance anxiety. Researchers should now work towards trying to detect what type of vulnerability contexts tend to favour the development of such personal profiles, and towards primary prevention by emphasizing positive developmental aspects (Orejudo \& Teruel, 2009).

Regarding the adaptation process, based on the results, the K-MPAI has provided us with a measure featuring good psychometric properties that make it both valid and reliable for the measurement of performance anxiety in music students in Spain. The scales of 'specific cognitions' and 'context' have been proven to have particularly high consistency and validity. The same cannot be said, however, of the helplessness scale. The four-factor model seems to indicate that the helplessness scale should be subdivided into two related factors - controllability and depression - which correlate highly with one another $(r=.625)$. On the other hand, the fourfactor model does not provide any further significant advantages vis-à-vis the more parsimonious three-factor model. To complete the validation process, further studies will need to incorporate further data concerning temporal stability as well as convergent, discriminant and criterion-related validity.

However, the inclusion of a validation process in the confirmatory factor analysis techniques allowed us to refine and simplify our evaluation tool by adjusting those techniques to the theoretical framework. In the process, we deleted certain items previously isolated in the exploratory factor analysis, in the same way as in the study conducted by Kenny et al. (2004). However, we cannot say whether this phenomenon is attributable to the questionnaire in its original form, or whether it emerged in the process of its Spanish adaptation. Confirmatory studies need to be conducted on the original measure. In this sense, Kenny's (2009b) more recent version of the same measure featuring more items permits us to explore certain aspects more closely. For the helplessness factor, the new model proposes four subfactors ([1] Depression/Hopelessness; [9] Controllability; [11] Trust; [12] Pervasive performance anxiety), two of which would correspond 
with those we isolated in our own four-factor model. However, the 26-item questionnaire does not provide sufficient basis to study the remaining factors in greater depth.

We must acknowledge the limitations of the current study. First, from a theoretical point of view, the measure adapted in this study assessed three components of psychological vulnerability; however, we believe that more specific experiences can be studied in further depth. Together with the specific cognitions of performance, such factors could be found among the numerous elements which make up specific vulnerability. Researchers such as Papageorgi et al. (2007) have shown that the study of the previous training context, experiences of previous performances, the type of repertoire to be played and the problem of limited, inadequate preparation on the part of the interpreter are all influential factors that can originate and perpetuate performance anxiety in interpreters.

Moreover, this measure needs to be validated in other populations and settings - for example, with professional musicians, or university students at earlier stages of their training. It would also be of interest to analyse the measure's capability to detect changes in the population after they have undergone treatment. From our point of view, it would be useful if other measures such as this one - capable of comprehensively assessing performance anxiety within a broad theoretical framework - also existed. A better understanding of this problem could be gained by adding more elements related to proximal performance concerns or associated with learning experiences undergone in music training.

\section{Funding}

This research received no specific grant from any funding agency in the public, commercial, or not-forprofit sectors.

\section{References}

Abad, F. J., Olea, J., Ponsoda, V., \& García, C. (2011). Medición en Ciencias Sociales y de la Salud [Measurement in Social and Health Sciences]. Madrid, Spain: Síntesis.

American Psychiatric Association. (1994). Diagnostic and Statistical Manual of Mental Disorders (4th ed.). Washington, DC: American Psychiatric Association.

Arrau, C. (1983). Mirando hacia el psicoanálisis [Looking to the psychoanalysis]. Revista Universitaria, 10, 9-13.

Barlow, D. (2000). Unraveling the mysteries of anxiety and its disorders from the perspective of emotion theory. American Psychologist, 55, 1247-1263.

Brown, T. A. (2006). Confirmatory factor analysis for applied research. New York, NY: The Guilford Press.

Dalia Cirujeda, G. (2004). Cómo superar la ansiedad escénica en músicos. [Overcoming music performance anxiety]. Madrid, Spain: Mundimúsica Ediciones.

Figueirido Rocha, S., Dias-Neto, E., \& Farid Gattaz, W. (2011). Ansiedade na performance musical: Traduçao, adaptaçao e validaçao do Kenny Music Performance Anxiety Inventory (K-MPAI) para la lingua portuguesa [Music performance Anxiety: Translation, adaptation and validation of Kenny Music Performance Anxiety Inventory (K-MPAI) to Portuguese language]. Revista Psicología clínica, 38(6), 217-221.

Hoffman, S. L., \& Hanrahan, S. J. (2012). Mental skills for musicians: Managing music performance anxiety and enhancing performance. Sport, Exercise, and Performance Psychology, 1(1), 17-28.

Herrera, L., \& Manjón, G. J. (2013). Ansiedad escénica musical en estudiantes de flauta travesera [Music performance anxiety in flute students]. Eufonía. Didáctica de la música, 57, 43-55.

Kaspersen, M., \& Götestam, K. G. (2002). A survey of music performance anxiety among Norwegian music students. European Journal of Psychiatry, 16(2), 69-80.

Kenny, D. T. (2008). Music Performance Anxiety. International Handbook of Musicians' Health and Wellbeing. Oxford, UK: Oxford University Press. 
Kenny, D. T. (2009a). Negative emotions in music making: Performance anxiety. In P. Juslin \& J. Sloboda (Eds.), Handbook of music and emotion: Theory, Research, Applications (pp. 425-451). Oxford, UK: Oxford University Press.

Kenny, D. T. (2009b). The factor structure of the revised Kenny Music Performance Anxiety Inventory. International Symposium on Performance Science (pp. 37-41). Utrecht: Association Européenne des Conservatoires.

Kenny, D. T. (2011). The Psychology of Music Performance Anxiety. Oxford, UK: Oxford University Press.

Kenny, D. T., \& Ackermann, B. (2015). Performance related musculoskeletal pain and depression in professional orchestral musicians. Psychology of Music, 43(1), 43-60.

Kenny, D. T., Davis, P., \& Oates, J. (2004). Music performance anxiety and occupational stress amongst opera chorus artists and their relationship with state and trait anxiety and perfectionism. Journal of Anxiety Disorders, 18, 757-777.

Kenny, D. T., Driscoll, T., \& Ackermann, B. (2014). Psychological well-being in professional orchestral musicians in Australia: A descriptive population study. Psychology of Music, 42(2), 210-232.

Kenny, D. T., Fortune, J., \& Ackermann, B. (2009, December). What predicts performance excellence in tertiary level music students? In A. Williamon, S. Pretty \& R. Buck (Eds.), Proceedings of the International Symposium on Performance Science (pp. 487-492). Utrecht, The Netherlands: European Association of Conservatoires (AEC).

Kenny, D. T., Fortune, J., \& Ackermann, B. (2013). Predictors of music performance anxiety in skilled tertiary level flute players. Psychology of Music, 41, 304-326.

Kenny, D. T., \& Osborne, M. (2006). Music performance anxiety: New insights from young musicians. Advances in Cognitive Psychology, 2(2-3), 103-112.

Lee, S. (2002). Musicians' performance anxiety and coping strategies. American Music Teacher, 52(1), 36-39.

Marchant-Haycox, S. E., \& Wilson, G. D. (1992). Personality and stress in performing artists. Personality and Individual Differences, 13, 1061-1068.

McAllister, J. A. (2011). Performance Anxiety Amongst Middle School-Aged Wind Instrumentalists as Influenced by Variations in Delivery of Instructional Script Given by Adjudicators During Sight Reading (Unpublished master's thesis in Musical Education Science). Florida International University, Miami, FL.

McDonald, R. P., \& Ho, M. H. R. (2002). Principles and practice in reporting structural equation analyses. Psychological Methods, 7, 64-82.

Nagel, J. J., Himle, D. P., \& Papsdorf, J. D. (1989). Cognitive-behavioral treatment of musical performance anxiety. Psychology of Music, 17, 12-21.

Orejudo, S., \& Teruel, M. P. (2009). Una mirada evolutiva al optimismo en la edad escolar. Algunas reflexiones para padres, educadores e investigadores [Evolutive aproach to optimism in scholar age. Some thoughts for parents, educators and researchers]. Revista Interuniversitaria de Formación del Profesorado, 23(3), 129-158.

Osborne, M. S., Kenny, D. T., \& Holsomback, R. (2005). Assessment of MPA in late childhood. International Journal of Stress Management, 12, 312-330.

Papageorgi, I., Creech, A., \& Welch, G. (2011). Perceived performance anxiety in advanced musicians specializing in different musical genres. Psychology of Music, 41(1), 18-41.

Papageorgi, I., Hallam, S., \& Welch, G. F. (2007). A conceptual framework for understanding musical performance anxiety. Research Studies in Music Education, 28, 83-107.

Petrovich, A. (2004). Performance anxiety: How teachers can help. American Music Teacher, 53(3), 24-27.

Salmon, P. (1990). A psychological perspective on Musical Performance Anxiety - a review of the literature. Medical Problems of Performing Artists, 5(1), 1-11.

Sandgren, M. (2002). Voice, soma, and psyche: A qualitative and quantitative study of opera singers. Medical Problems of Performing Artists, 17, 11-21.

Sommer, L. (2013). Exam preparation: The influence of action control, procrastination and examination experience on students' goal intention and implementation intention. Electronic Journal of Research in Educational Psychology, 11(3), 603-630. 
Spahn, C. (2006). Lampenfieber und Aufführungsangst bei Musikern - Grundlagen und Therapie [Stage fright and performance anxiety in musicians - basics and therapy]. Med Welt, 57, 559-563.

Spielberger, C. D., Gorsuch, R., \& Lushene, R. (1970). Manual for the State - Trait Anxiety Inventory. Palo Alto, CA: Consulting Psychologist Press.

Studer, R., Danusera, B., Hildebrandt, H., Arial, M., \& Gomez, P. (2011). Hyperventilation complaints in music performance anxiety among classical music students. Journal of Psychosomatic Research, 70, $557-564$.

Taborsky, C. (2007). Musical performance anxiety: A review of literature. Applications of Research in Music Education, 26, 15-25.

Van Kemenade, J. F. L. M., Van Son, M. J. M., \& Van Heesch, N. C. A. (1995). Performance anxiety among professional musicians in symphonic orchestras: A self-reported study. Psychological Reports, 77, $555-562$.

Weiber, R., \& Mühlhaus, D. (2009). Strukturgleichungsmodellierung - Eine anwendungsorientierte Einführung in die Kausalanalyse mit Hilfe von AMOS, SmartPLS und SPSS [Structure, equation modelling - An application-oriented introduction to the causal analysis using AMOS, SmartPLS and SPSS]. Berlin, Germany: Springer Verlag.

Wesner, R. B., Noyes, R., \& Davis, T. L. (1990). The occurrence of performance anxiety among musicians. Journal of Affective Disorders, 18, 177-185.

Wilson, G. D. (1997). Performance anxiety. In D. J. Hargreaves \& A. C. North (Eds.), The social psychology of music (pp. 229-248). Oxford, UK: Oxford University Press.

Wolfe, M. L. (1989). Correlates of adaptive and maladaptive musical performance anxiety. Medical Problems of Performing Artists, 4(1), 49-56.

Yoshie, M., Kudo, K., Murakoshi, T., \& Ohtsuki, T. (2009). Music performance anxiety in skilled pianists: Effects of social-evaluative performance situation on subjective, autonomic, and electromyographic reactions. Experimental Brain Research, 199(2), 117-126. 